\title{
Fatal intoxications among non-drug addicts in Eastern Denmark over a five-year period (2003-2007)
}

This article was published in the following Dove Press journal:

Research and Reports in Forensic Medical Science

19 June 2012

Number of times this article has been viewed

\author{
Jannie Hecht Pedersen \\ Sys Stybe Johansen \\ Camilla Haugereid \\ Lise Skyttegaard Balkert \\ Kristian Linnet \\ Section of Forensic Chemistry \\ and Section of Forensic Pathology, \\ Department of Forensic Medicine, \\ Faculty of Health Sciences, University \\ of Copenhagen, Denmark
}

Correspondence: Sys Stybe Johansen Section of Forensic Chemistry, Frederik Femte Vej I I, DK-2I00 Copenhagen, Denmark $\varnothing$

Tel +453532624 I

Fax +4535326085

Email ssj@forensic.ku.dk
Background: This study describes fatal intoxications among non-drug addicts in Eastern Denmark over a five-year period (2003-2007), and the data are compared with two similar five-year studies from 1992-1996 and 1998-2002.

Method and Results: Among 2663 medicolegal autopsies performed during the study period, 428 fatal intoxications in non-drug addicts were detected. Sixty-three percent were caused by pharmaceuticals, $20 \%$ by carbon monoxide, and $15 \%$ by ethanol. Comparable with previous studies, carbon monoxide, ethanol, methadone, and morphine were the most common fatal substances, although new pharmaceuticals were observed among the ten most lethal substances, such as tramadol. Furthermore, older pharmaceuticals with narrow therapeutic windows such as propoxyphene and ketobemidone were almost not present. This study also briefly mentions alcoholic ketoacidosis as a cause of fatal intoxications.

Conclusion: The pattern of fatal intoxications could, for some pharmaceuticals, be related to the number of treatments, although other unknown factors also contribute.

Keywords: fatal poisonings, fatal intoxications, non-drug addicts, pharmaceuticals, ethanol, carbon monoxide

\section{Introduction}

Investigations of fatal intoxications among non-drug addicts are valuable in order to achieve information on applied dangerous drugs, accessible pharmaceuticals, and their misuse. The cause and manner of death, age, and gender among these fatalities is interesting to follow over time and might show important patterns that can be used preventively. The purpose of this study is to evaluate and determine intoxication deaths among non-drug addicts in Eastern Denmark over a five-year period (2003-2007) and relate the results to similar surveys from 1992-1996 and 1998-2002. ${ }^{1,2}$ These former studies showed that morphine, carbon monoxide (+ cyanide), ethanol, and methadone were the most frequent fatal substances, but poisoning with various weak-acting analgesics, antidepressants, and antipsychotics were also frequently observed. Comparison of these results with the presently described five-year period is very informative and can reveal trends in fatal intoxications, as well as highlight some medicinal hazards of interest to the society. Interventions and new laws concerning dangerous drugs will influence the pattern, and renewed assessments can form the basis for making new interventions. In the present context, we do not consider deaths of drug addicts. Addiction to illegal drugs is a complex issue involving various biological and social aspects that deserves special focus. Intervention is based on making illegal drugs less available, preventing initiation of drug use in young people, and reducing drug use 
in established drug users. ${ }^{3}$ Further, maintenance therapy in opioid-dependent individuals using methadone or buprenorphine is an important aspect. ${ }^{4}$

\section{Materials and methods}

The study includes material from medicolegal autopsies at the Institute of Forensic Medicine, University of Copenhagen performed from 2003 to 2007, where the police requested forensic investigation based on the Ministry of Justice circular of November 21, 1995. ${ }^{5}$ The institute performs medicolegal autopsies for Zealand, surrounding islands, and Bornholm, which represents a population of approximately 2.4 million people. ${ }^{6}$ In the period 2003-2007, 3847 medicolegal autopsies were performed, of which forensic chemical investigation were requested in 2663 (69\%). Forensic chemical investigations are conducted in case of suspicion of intoxication and/or lack of information on the cause of death after autopsy, and are based on analysis of femoral blood, apart from a minor number of cases, where analysis is performed on muscle tissue. Screening was performed by chromatographic methods like gas chromatography-mass spectrometry and high-pressure liquid chromatography-photodiode array detection, and immunoassays. Positive results were confirmed by liquid chromatography-mass spectrometry/mass spectrometry or gas chromatography-mass spectrometry. Most cases were examined for multiple drugs, both legal and illegal, and poisons. However, this study does also include autopsies that were submitted only for specific examinations, such as ethanol or carbon monoxide. It should be noted that suspected suicide in Denmark typically only leads to forensic autopsy when there is doubt about the cause or manner of death, and thus the suicides in this survey represent only a small proportion of the total number of suicides by intoxication. Cases where the combination of various substances in non-lethal concentrations was considered lethal (combination intoxications) were included. Cases in which the deceased was a drug addict were excluded. Drug addicts ${ }^{7}$ were defined as persons who according to information from the police and/or autopsy report are known or observed to have abused drugs intravenously and/ or abused drugs listed in the Single Convention on Narcotic Drugs 1961, schedule I (including heroin, morphine, and cocaine), and/or the International Convention on Psychotropic Substances 1971, schedules I and II (including amphetamines and lysergic acid diethylamide). Cases were also excluded if the cause of death was something other than intoxication, such as a high blood alcohol in an alcoholic who died as a result of blunt trauma. Conversely, cases with non-fatal concentrations, where the deceased had a prolonged hospitalization due to intoxication with, for instance, paracetamol for suicide purposes, were included. Additionally, cases where the cause of death was alcoholic ketoacidosis were collected. Alcoholic ketoacidosis is an indirect intoxication with ethanol, and for that reason we separated these cases from the other material in the survey.

\section{Results}

During the study period, 428 deaths due to intoxication were identified (alcoholic ketoacidosis not included) in nondrug addicts, with the number of annual cases as follows: 106 in 2003, 90 in 2004, 89 in 2005, 63 in 2006, and 80 in 2007, respectively. Cases consisted of 230 (54\%) males and 198 (46\%) females (Figure 1). The highest mortality was observed for men 40-49 years of age $(n=83)$ and women aged $50-59$ years $(n=52)$. In 46 cases $(11 \%)$, no substance

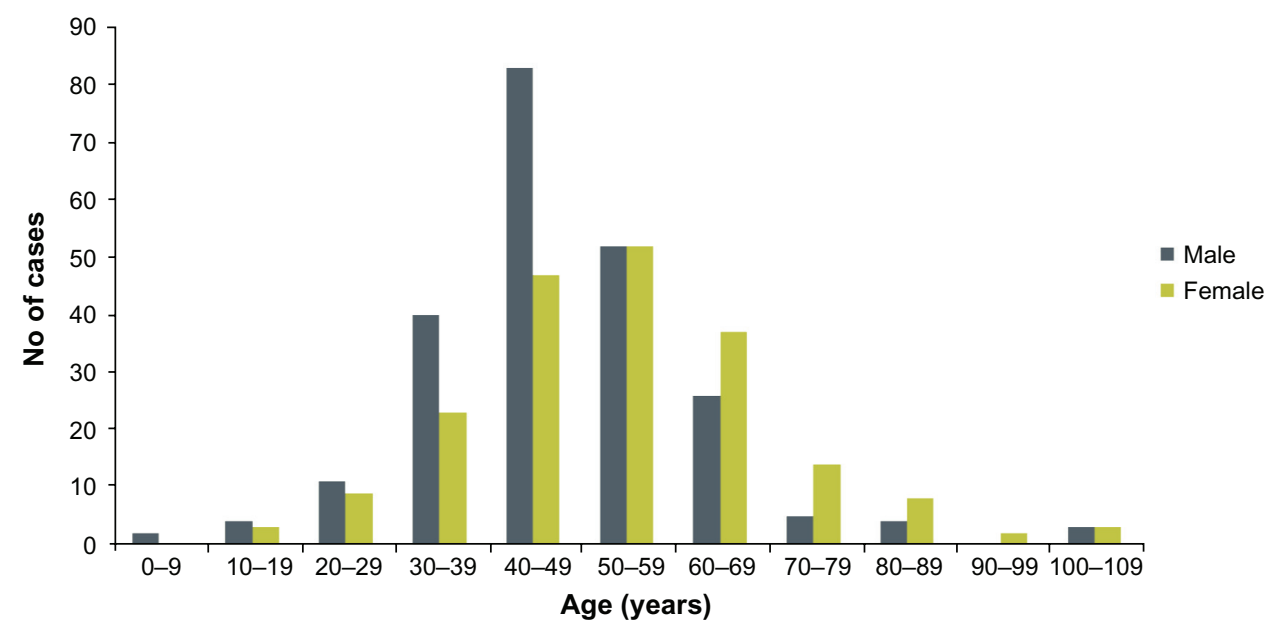

Figure I Age distribution of the 428 fatal intoxications among non-drug addicts in Eastern Denmark from 2003-2007. 
was found at a lethal concentration and the cause of death was estimated to be combination intoxications. In the remaining 382 cases, one or several substances were observed at a lethal concentration; among these, one single-substance at a lethal concentration was observed in 334 cases (78\%) and multiple substances at lethal concentration were observed in $48(11 \%)$ cases. In the 382 fatal intoxications with one or more substances at a lethal concentration, 241 (63\%) involved pharmaceuticals, $56(15 \%)$ deaths were caused by ethanol, two $(0.5 \%)$ were due to both pharmaceuticals and alcohol, and seven (1.8\%) were caused by other poisons such as isopropanol, gasoline, and butane. Seventy-six (20\%) deaths were due to carbon monoxide and/or cyanide. Cyanide intoxication is included in the investigation of carbon monoxide intoxication, since all the observed cases were fire-related deaths. Figure 2 shows the fatal intoxications involving pharmaceuticals divided in indication groups, and examples of the most common pharmaceuticals are given. The number of observations in the figure does not directly correlate with the total number of cases, because cases with more than one toxic substance at a lethal concentration were included once for each substance. Among the fatal pharmaceuticals found, the strong opioids were the largest group (31\%), followed by weak opioids, antipsychotics, antidepressants, and weak-acting analgesics. Nearly 55\% of the recorded pharmaceuticals were analgesics, and almost one-third were pharmaceuticals for mental illnesses.
Table 1 shows the most common intoxication agents found at lethal concentrations, corresponding to 440 in the 382 fatal intoxication cases. Amitriptyline and nortriptyline are counted together, since nortriptyline is an active metabolite of amitriptyline as well as an individual pharmaceutical. Furthermore, escitalopram was included with citalopram, because it is the S-enantiomer of citalopram. In total, 57 various substances were found at lethal concentrations. The most common intoxication agents were carbon monoxide/cyanide, ethanol, methadone, and morphine. Cases involving one or more of these substances at a lethal concentration were 211 , equivalent to $55 \%$ of the 382 cases. Among the 46 cases of combination intoxications (cases with no substance at a lethal concentration), ethanol was involved in 31 (67\%). Ethanol was typically in combination with antidepressants and/or benzodiazepines and/ or antipsychotics. In the remaining cases of combination intoxications, benzodiazepines and/or antidepressants and/ or analgesics were typically seen.

Ethanol was considered as contributing to the fatality of the intoxication in 42 single-substance intoxications, eight multiple-substance intoxications, and 31 combination intoxications, representing a total of 81 cases $(19 \%)$. Combined with cases of acute ethanol intoxications, ethanol was the cause of death or contributed to fatal intoxications in 139 cases (32\%). Furthermore, there were also 89 deaths from alcoholic ketoacidosis during the study period. By including

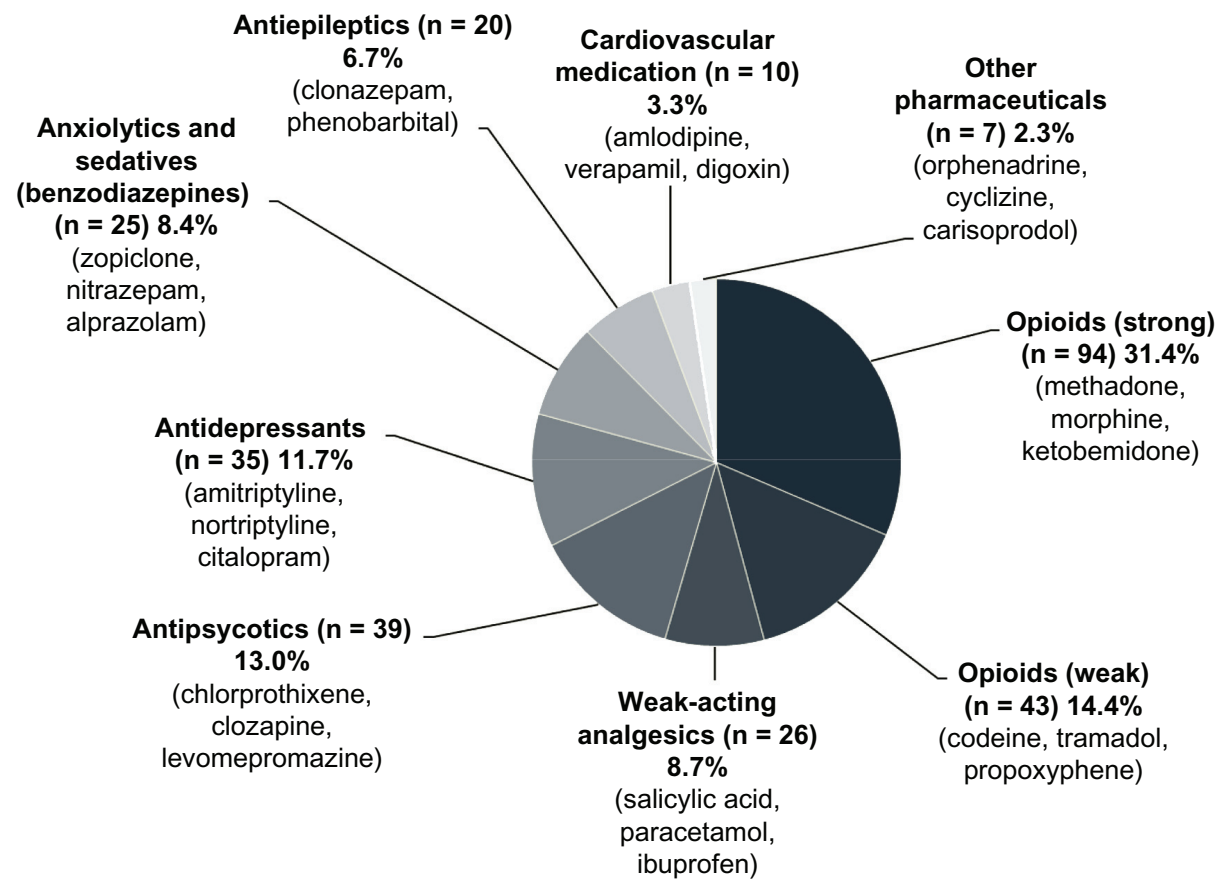

Figure 2 Distribution of pharmaceutical groups associated with fatal intoxications among non-drug addicts in Eastern Denmark with examples of frequent pharmaceuticals. 
Table I The 25 most frequent intoxication substances in lethal concentrations among non-drug addicts in Eastern Denmark from 2003-2007 with specifications on manner of deaths. Intoxication substances with two or fewer deaths within the five-year period are omitted, including one death with buprenorphine (see Discussion section)

\begin{tabular}{|c|c|c|c|c|c|c|}
\hline \multirow[t]{2}{*}{ Substance } & \multirow{2}{*}{$\begin{array}{l}\text { Cases }(n) \\
2003-2007\end{array}$} & \multicolumn{5}{|c|}{ Manner of death } \\
\hline & & Suicide & Accident & Unknown & Homicide & Males \\
\hline Carbon monoxide/cyanide & 76 & $5(6.6 \%)$ & $67(88.2 \%)$ & $3(3.9 \%)$ & $\mathrm{I}(\mathrm{I} .3 \%)$ & $40(52.6 \%)$ \\
\hline Ethanol & 58 & I (I.7\%) & 53 (91.4\%) & $4(6.9 \%)$ & & $36(62.1 \%)$ \\
\hline Methadone & 46 & $7(15.2 \%)$ & $31(67.4 \%)$ & $8(17.4 \%)$ & & $33(71.7 \%)$ \\
\hline Morphine & 33 & $12(36.4 \%)$ & $12(36.4 \%)$ & $9(27.3 \%)$ & & $19(57.6 \%)$ \\
\hline Codeine & 25 & $10(40.0 \%)$ & $7(28.0 \%)$ & $8(32.0 \%)$ & & I 4 (56.0\%) \\
\hline Ami-/Nortriptyline & 17 & II (64.7\%) & $4(23.5 \%)$ & $2(11.8 \%)$ & & 7 (4I.2\%) \\
\hline Tramadol & 14 & $3(21.4 \%)$ & $6(42.9 \%)$ & $5(35.7 \%)$ & & $8(57.1 \%)$ \\
\hline Ketobemidone & 13 & $4(30.8 \%)$ & $6(46.2 \%)$ & $3(23.1 \%)$ & & $5(38.5 \%)$ \\
\hline Acetylsalicylic acid* & 13 & $8(61.5 \%)$ & $4(30.8 \%)$ & I (7.7\%) & & 7 (53.8\%) \\
\hline Chlorprothixene & 12 & $2(16.7 \%)$ & $4(33.3 \%)$ & $6(50.0 \%)$ & & 7 (58.3\%) \\
\hline Paracetamol & 12 & $6(50.0 \%)$ & $2(16.7 \%)$ & $4(33.3 \%)$ & & $4(33.3 \%)$ \\
\hline Clonazepam & 10 & $2(20.0 \%)$ & $5(50.0 \%)$ & $3(30.0 \%)$ & & $8(80.0 \%)$ \\
\hline Zopiclone & 9 & 7 (77.8\%) & I (II.I\%) & I (II.I\%) & & $4(44.4 \%)$ \\
\hline (Es-)Citalopram & 8 & $3(37.5 \%)$ & $3(37.5 \%)$ & $2(25.0 \%)$ & & $3(37.5 \%)$ \\
\hline Clozapine & 8 & I (I2.5\%) & $3(37.5 \%)$ & $4(50.0 \%)$ & & $4(50.0 \%)$ \\
\hline Nitrazepam & 8 & $4(50.0 \%)$ & $2(25.0 \%)$ & $2(25.0 \%)$ & & $4(50.0 \%)$ \\
\hline Levomepromazine & 7 & $2(28.6 \%)$ & $4(57.1 \%)$ & I (I4.3\%) & & $3(42.9 \%)$ \\
\hline Phenobarbital & 6 & I (16.7\%) & $3(50.0 \%)$ & $2(33.3 \%)$ & & $0(0.0 \%)$ \\
\hline Olanzapine & 5 & I (20.0\%) & $3(60.0 \%)$ & I (20.0\%) & & $3(60.0 \%)$ \\
\hline Amlodipine & 4 & $3(75.0 \%)$ & & I (25.0\%) & & $2(50.0 \%)$ \\
\hline Orphenadrine & 4 & $4(100.0 \%)$ & & & & $2(50.0 \%)$ \\
\hline Alprazolam & 3 & $2(66.7 \%)$ & I (33.3\%) & & & $2(66.7 \%)$ \\
\hline Propoxyphene & 3 & I (33.3\%) & $2(66.7 \%)$ & & & $0(0.0 \%)$ \\
\hline Verapamil & 3 & $2(66.7 \%)$ & & I (33.3\%) & & $3(100.0 \%)$ \\
\hline Zuclopenthixol & 3 & I (33.3\%) & & $2(66.7 \%)$ & & I (33.3\%) \\
\hline
\end{tabular}

Note: *Acetylsalicylic acid metabolizes rapidly after consumption to salicylic acid, which is the target in laboratory analyses.

these, it was observed that alcohol was involved in 228 cases (44\%) out of a total of 517 cases, either as cause of death or as a contributing factor.

The manner of death for the 428 cases constituted 252 accidents $(59 \%), 87$ suicides $(20 \%)$, one homicide $(0.2 \%)$, and 88 unknown (21\%). Among the accident cases, $59 \%$ were male and the mean age was 48 years for males and 55 years for females. It should be noted that $46 \%$ of all accident cases consisted of males aged 30-59 years. The most frequently detected substances in lethal concentrations among accidents were carbon monoxide/cyanide, ethanol, methadone, and morphine. Among the suicide cases, $54 \%$ were female, and $36 \%$ of the suicide cases were multiple-substance intoxications with more than one substance at a lethal concentration. The most common intoxication substances in suicides were morphine, amitriptyline, nortriptyline, codeine, acetylsalicylic acid, methadone, and zopiclone. The average age of suicide cases was 53 years for females and 48 years for males. During the study period, one homicide due to intoxication was found, which related to intoxication by carbon monoxide in a fire, and not a poison murder in the traditional sense.
In the cases where the manner of death was unknown, $52 \%$ were female. The most frequently detected substances in these cases at lethal concentration were morphine, codeine, methadone, chlorprothixene, and tramadol. Eighteen percent of the unknown cases were combination intoxications.

\section{Discussion}

The number of annual fatal intoxications over the five-year study period showed a slight decline from 106 cases in 2003 to 80 in 2007. There was an average of 86 intoxications per year, which is marginally lower than in the previous period (1998-2002) with 89 intoxications per year, ${ }^{1}$ and less than in the period 1992-1996 with 106 intoxications per year. ${ }^{2}$ The number of single-substance (334) and multiple-substance intoxications (48) during this period was almost identical to those in the previous study period (1998-2002), while combination intoxications were slightly lower $(46 ; 11 \%)$ compared with those in the previous period (1998-2002, $\mathrm{n}=67 ; 15 \%){ }^{1}$

Fifty-nine percent of the deaths in 2003-2007 were accidental, compared with only $32 \%$ in $1998-2002,{ }^{1}$ which may 
be due to the many unknown causes of death in the previous period, and an improvement in the registration of causes of death in the current period. One intoxication homicide was observed during the period (carbon monoxide intoxication in connection with a fire).

Table 2 shows the 10 most common intoxicating substances for 2003-2007 compared with the two earlier studies. In the investigation from 1992-1996² it was chosen to count only the "most substantial substance" in multiplesubstance intoxications, and therefore this investigation may be deficient regarding the number of intoxicating substances, which may affect the ranking of the most common substances. Carbon monoxide/cyanide has become the most frequently observed substance with 76 detections as opposed to 59 in 1998-2002; morphine was previously the most frequently observed substance. Most of the carbon monoxide/ cyanide intoxications occurred in connection with fires where a competing cause of death is extensive burns. The majority of carbon monoxide/cyanide intoxications in this study were accidents. The second most frequent cause of death in this study was acute ethanol intoxication with 58 cases compared with 55 cases in 1998-2002. The high number of cases where ethanol contributed to the fatal intoxication, including the many deaths caused by alcoholic ketoacidosis, underlines the toxic potential of this easily available substance.

In the following discussion, we relate the intoxication deaths by substance to the number of people treated with a given pharmaceutical, as stated by the Danish Medicines Agency. In addition to the number of people treated, there may be many other reasons for the changes over time in the number of fatal intoxications involving a particular pharmaceutical. For instance, selection of cases for medicolegal autopsies, examination scope, changes in the characteristics of the population treated with a given product, improved hospital treatment of intoxication cases, and changes in typical substances used for suicides may all affect the data. Our results may help to raise awareness that certain pharmaceuticals should be prescribed and used with great caution.

The opioid methadone advanced from the fourth to third most frequent substance, although the number of intoxications changed only slightly. The number of people treated with methadone (substitution treatment excluded) remained relatively stable at around 7500 in the period 1998-2007. ${ }^{8}$ Typical indications for the use of methadone were chronic pain.

There may be some drug addicts included in our study cohort, who were not registered as such, because of lack of information. The number of fatal intoxications among drug addicts with methadone in Denmark increased during the same time period..$^{9,10}$ An alternative to methadone is the partial opioid agonist buprenorphine. The number of people treated for pain with buprenorphine increased from 10,380 in 1998 to 19,626 in $2007 .{ }^{8}$ Despite the high number of people treated with buprenorphine, there was only one death in the study material caused by this substance in 2003-2007. Its lower toxicity also explains why it is recommended by the National Board of Health in Denmark as the first-line drug for detoxification of opioid dependence. ${ }^{11}$ The number of deaths caused by the opioid morphine decreased from 62 in 1998-2002 to 33 in 2003-2007, which among other reasons might be related to the fact that the number of people treated

Table 2 The 10 most frequent intoxication substances among non-drug addicts in Eastern Denmark from 2003-2007 compared with two similar studies from 1992-1996 and 1998-2002 respectively

\begin{tabular}{|c|c|c|c|c|c|c|c|}
\hline \multicolumn{3}{|c|}{ 2003-2007 } & \multicolumn{3}{|c|}{$1998-2002$} & \multicolumn{2}{|c|}{ | $992-1996$} \\
\hline No & Substance & Observations & No & Substance & Observations & No & Substance \\
\hline I & Carbon monoxide & 76 & I & Morphine & 62 & I & Morphine \\
\hline 2 & Ethanol & 58 & 2 & Carbon monoxide/cyanide & 59 & 2 & Ethanol \\
\hline 3 & Methadone & 46 & 3 & Ethanol & 55 & 3 & Carbon monoxide/cyanide \\
\hline 4 & Morphine & 33 & 4 & Methadone & 50 & 4 & Ketobemidone \\
\hline 5 & Codeine & 25 & 5 & Salicylic acid & 23 & 5 & Ami/nortriptyline \\
\hline 6 & Ami/nortriptyline & 17 & 6 & Ketobemidone & 21 & 6 & Propoxyphene \\
\hline 7 & Tramadol & 14 & 7 & Codeine & 18 & 7 & Methadone \\
\hline 8 & Ketobemidone & 13 & 8 & Ami/nortriptyline & 17 & 8 & Salicylic acid \\
\hline 9 & Salicylic acid & 13 & 9 & Citalopram & II & 9 & Phenobarbital \\
\hline 10 & Chlorprothixene & 12 & 10 & Chlorprothixene & 10 & 10 & Paracetamol \\
\hline \multirow[t]{5}{*}{10} & Paracetamol & 12 & 10 & Paracetamol & 10 & & \\
\hline & & & 10 & Propoxyphene & 10 & & \\
\hline & & & \multicolumn{5}{|c|}{ Other substances of interest } \\
\hline & & & \multicolumn{2}{|c|}{ Phenobarbital } & 5 & & \\
\hline & & & \multicolumn{2}{|c|}{ Tramadol } & 4 & & \\
\hline
\end{tabular}


with morphine decreased from 36,167 in 1998 to 29,295 in 2007. ${ }^{8}$ The current investigation detected 14 deaths due to the opioid tramadol in 2003-2007, an apparent increase compared with the previous period with four deaths. This trend was also observed in fatal intoxications among Danish drug addicts. ${ }^{9,10}$ The number of people treated with tramadol increased from 144,824 in 1998 to 242,874 in $2007 .{ }^{8}$ This may partially explain the increase in tramadol deaths, and special focus on this trend in the future is recommendable.

Deaths from codeine rose from 18 in 1998-2002 to 25 in 2003-2007. Kodimagny $l^{\circledR}$, a combination product of codeine and acetylsalicylic acid, is the only codeine-containing product available over the counter in Denmark. In Kodimagnyl intoxications, the typical observation is codeine as well as salicylic acid, at lethal concentrations. Since there was a decrease in the number of salicylic acid, intoxications in 2003-2007, the increase of fatal codeine intoxications is not likely due to an increased amount of intoxications with Kodimagnyl. Despite this, at least eight fatal intoxications that could be caused by intake of Kodimagnyl (ie, both salicylic acid and codeine at a lethal concentration) were observed, of which six were suicides, one was an accident, and one case was of unknown manner of death. The codeine in the remaining 17 cases therefore most likely originated from prescription products containing codeine. The number of people treated with codeine was highest in 2001 at 71,373 and declined to 58,297 in $2007 .{ }^{8}$ There is no immediate correlation between the number of treatments and fatal intoxications with codeine. The relatively high number of suicides (at least $40 \%$ of these deaths) should highlight the need for extra care when prescribing products with codeine.

Deaths due to the weak-acting analgesic, acetylsalicylic acid, decreased from 23 in 1998-2002 to 13 in 2003-2007, which seems to represent a positive development for this pharmaceutical, despite the fact that this has been available in liberalized over the counter sale since October 1, 2001. ${ }^{12}$ According to an analysis on drug consumption by the Danish Medicines Agency, ${ }^{13}$ a 20 percent decrease in over the counter sales of acetylsalicylic acid during the period 2004-2008 was observed, which may partially explain the declining number of deaths. In addition to being used as a painkiller, acetylsalicylic acid is also used in low doses as an anticoagulant. The number of people on anticoagulant acetylsalicylic acid therapy rose in the period 2000-2007 according to statements from the Danish Medicines Agency, and people treated for pain decreased from 2000 to $2007 . .^{14,15}$ It is tempting to assume that accidental overdoses of salicylic acid are more frequent in the group of patients treated for pain than in those treated for anticoagulation, because the doses for pain treatment is usually more than 20 times higher. The decreasing number of people treated for pain thus may be related to the likewise declining number of observed salicylic acid intoxications. Of the 13 deaths with salicylic acid in 2003-2007, eight were suicides (of which six were possible Kodimagnyl intoxications) compared with 13 in the period 1998-2002.

The number of deaths from the opioid, ketobemidone, decreased from 21 in 1998-2002 to 13 in 2003-2007. A similar trend was observed among deaths of Danish drug addicts. ${ }^{9,10}$ During the same period, the number of people treated with ketobemidone more than halved from 52,863 in 1998 to 26,144 in $2007 .{ }^{8}$ Ethanol was involved in almost $70 \%$ of the ketobemidone deaths, underlining the risk of the combination of ketobemidone and ethanol. The weak opioid propoxyphene is no longer among the 10 most frequent intoxication substances, and only three deaths were observed in 2003-2007 compared with 10 in the previous period. The number of people treated with propoxyphene decreased from 16,062 in 1998 to 3719 in $2007^{8}$ possibly due to warnings about the substance. ${ }^{16,17}$ Six deaths due to the barbituric acid derivative phenobarbital were observed in 2003-2007 compared with five in the previous period. This is despite the fact that the number of people treated with phenobarbital was halved during the period, from 8960 in 1998 to 4911 in $2007 .{ }^{8}$ Although the antidepressants amitriptyline and nortriptyline have risen from the eighth to the sixth most frequently fatal substance, the number of intoxications was stable at 17 . In the study from 1992-1996, there were approximately 33 deaths with amitriptyline or nortriptyline, so the number of fatal intoxications observed in the forensic material involving these medications has almost halved since the mid-nineties. This should be viewed in light of the fact that the number of people treated with amitriptyline or nortriptyline has risen nearly $25 \%$ from 1998 to $2007 .{ }^{8}$ At least 11 of the 17 deaths from amitriptyline or nortriptyline were suicides. When studying the newer antidepressants, such as (es)citalopram, it should be noted that these are no longer on the list of the 10 most frequent intoxication substances. There were eight deaths from intoxications with (es)citalopram in 2003-2007 and 11 deaths in the previous period. The number of people treated with citalopram doubled from 84,744 in 1998 to 158,324 in $2007 .{ }^{8}$ The number of people treated with escitalopram increased almost tenfold in the years after launch (2002) from 6268 in 2002 to 66499 in $2007 .{ }^{12}$ Thus, there is no apparent correlation between the number of people treated with amitriptyline, nortriptyline, or (es)citalopram and the number of fatal intoxications with these drugs. 
The pattern of changes in intoxication deaths is complex. Though it partly reflects the changes in the number of people treated with pharmaceuticals of high toxic potential, many other reasons that are not possible to account for in this study also exert influence.

\section{Conclusion}

This new five-year investigation of the period 2003-2007 showed that the average number of intoxications has declined slightly compared with previous five-year periods. The pattern of fatal intoxications corresponds to previous reports with regard to the distribution of single-substance and multiple-substance intoxications. The most frequent fatal substances are still carbon monoxide/cyanide, ethanol, methadone, and morphine. It is noted again that ethanol is of great importance in intoxication deaths. New trends are observed, particularly an increase in the number of tramadol intoxications and an almost elimination of older pharmaceuticals with narrow therapeutic windows, such as propoxyphene and ketobemidone. Particular care should be taken when using pharmaceuticals such as opioids that interact with ethanol, thereby increasing the risk of fatal intoxication.

\section{Disclosure}

The authors report no conflicts of interest in this work.

\section{References}

1. Johansen SS, Jacobsen C, Muller IB, et al. Intoxication deaths over five years (1998-2002) in Eastern Denmark. Ugeskr Laeger. 2006;168: 3326-3331. Danish.

2. Worm K, Steen Toft A, Toft J. Intoxication deaths over a 5-year period in Eastern Denmark. Ugeskr Laeger. 1999;161:6622-6625. Danish.

3. Strang J, Caulkins J, Fischer B, Foxtroft D, Humphreys K. Drug policy and the public good: evidence for effective interventions. Lancet. 2012; 379:71-83.
4. Tetrault JM, Fiellin DA. Current and potential pharmacological treatment options for maintenance therapy in opioid-dependent individuals. Drugs. 2012;72:217-228.

5. Ministry of Justice Circular no 11631 of November 21, 1995. Circular on the making of medico-legal autopsies and coroner, etc Justitsmn., j. nr. 1995-210-0008; 1995. Danish.

6. Statistics Denmark. BEF1A (2003-2006) and BEF1A07 (2007). Available from: http://www.statistikbanken.dk/May2010. Accessed March 4, 2012.

7. Ministry of Health Order No 698 of August 31, 1993. Order on drugs Health of., 5 kt., j.no 93-5320-6; 1993. Available from: https://www. retsinformation.dk/forms/R0710.aspx?id=137169. Accessed March 20, 2012. Danish.

8. Danish Medicines Agency. Product Statistics 1998-2007 obtained in May 2010 by personal correspondence with MSc, PhD. M. Laursen, Danish Medicines Agency, Medicines Control, Statistics and Analysis.

9. Pedersen CL, Steentoft A, Kringsholm B. Deaths among drug addicts in East Denmark in 2005. Ugeskr Laeger. 2006;168:4124-4127. Danish.

10. Simonsen KW, Normann PT, Ceder G, et al. Fatal intoxication in drug addicts in Norden in 2007. Forensic Sci Int. 2011;207:170-176.

11. The National Board of Health. Instructions on the prescription of addictive drugs and substitution treatment of individuals with opioid dependence. 1st ed. 2007. Available from: http://www.sst.dk/publ/ publ2007/EFT/Substitut_ordbehlvejl/afhaengighedlaegemidl.pdf/. Accessed March 4, 2012.

12. Ministry of Health. Order No 605 of June 25, 2001. Order on the Distribution of Prescription Drugs Outside Pharmacies. Copenhagen, Denmark: Danish Medicines Agency; 2001.

13. Danish Medicines Agency. Sale of deregulated OTC medicines 2004-2008; 2009. Available from: http://www.laegemiddelstyrelsen.dk/ statistik/forbrugsanalyser/salg-lib-2004-2008.asp/May2010. Accessed March 5, 2012.

14. Danish Medicines Agency. Pharmaceutical Statistics Denmark 20042008. Copenhagen, Denmark: Danish Medicines Agency; 2009.

15. Danish Medicines Agency. Pharmaceutical Statistics Denmark 2000 2004. Copenhagen, Denmark: Danish Medicines Agency; 2005.

16. Danish Medicines Agency. Consumption of strong analgesic drugs (opioids) in the primary sector 2004. Available from: http://www. laegemiddelstyrelsen.dk/publications/netpub/consumptionanalysis/opioid/ html/entire_publication.htm/May2010. Accessed March 5, 2012

17. Pro.medicin.dk, DLI A/S. Propoxyphene (Analgesic), April 2010. Available from: http://pro.medicin.dk/Laegemiddelgrupper/Grupper/227075/. March 5, 2012
Research and Reports in Forensic Medical Science

\section{Publish your work in this journal}

Research and Reports in Forensic Medical Science is an international, peer-reviewed, open access journal publishing original research, reports, reviews and commentaries on all areas of forensic medical science. The manuscript management system is completely online and includes a

\section{Dovepress}

very quick and fair peer-review system. Visit http://www.dovepress.com/ testimonials.php to read real quotes from published authors. 